\title{
Inventario y distribución de la herpetofauna en Jaizkibel
}

\author{
Jaizkibelgo herpetofaunaren inbentarioa eta banaketa \\ Inventory and distribution of herpetofauna in Jaizkibel
}

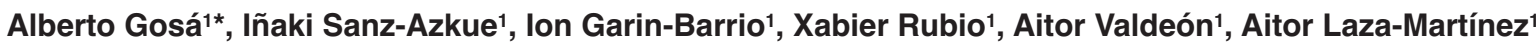 \\ 1' Departamento de Herpetología, Sociedad de Ciencias Aranzadi. Zorroagagaina, 11. 20014 Donostia-San Sebastián \\ *Correspondencia: agosa@aranzadi.eus
}

\section{RESUMEN}

Se ha actualizado el conocimiento de la comunidad herpetológica del macizo de Jaizkibel, después de largo tiempo de ausencia de publicaciones, mediante un inventario basado en trabajo de campo comprendido entre los meses de Abr. a Oct. de 2012, al que se han añadido observaciones acumuladas durante el último decenio. La comunidad está compuesta por 4 especies de anfibios y 11 especies de reptiles, en general distribuidas por la mayor parte del enclave y cuyo origen filogenético mayoritario es el continente europeo. No se ha podido confirmar la presencia del lagarto verdinegro Lacerta schreiberi Bedriaga, 1878, citado una sola vez en 1980.

PALABRAS CLAVE: Faunística, herpetos, inventarios, muestreo herpetológico, transectos.

\section{LABURPENA}

Urte luzez ez da argitalpenik jakitera eman Jaizkibelgo mendigunearen inguruan, gauzak honela 2012ko Api. eta Urr. artean egin diren laginketak baliatu dira Jaizkibelgo komunitate herpetologikoa eguneratzeko. Laginketetan jasotako informazioari azken hamarkadan bildutako behaketak gehitu zaizkio. Lau anfibio eta 11 narrasti espeziek osatzen dute komunitatea, eta orokorrean mendigune osotik barreiatzen dira, eta espezie gehienen jatorria Europan dago. Ezin izan da Schreiber muskerraren Lacerta schreiberi Bedriaga, 1978, presentzia baieztatu, nahiz eta 1980ko zita bakana ezagutu.

GAKO-HITZAK: Faunistikoa, herpetoak, inbentarioak, laginketa herpetologikoak, transektu.

\section{ABSTRACT}

After long time without publications we updated the herpetological community at the Jaizkibel massif with a preliminary inventory based on fieldwork conducted from Apr. to Oct. 2012. A certain number of sightings coming from the past decade were added. The community is composed of 4 species of amphibians and 11 reptiles generally distributed most of the enclave, and largely originated at the European continent After an old and single reference dated from 1980, we could not yet confirm the presence of the Schreiber's Green Lizard Lacerta schreiberi Bedriaga, 1878 in Jaizkibel.

KEY WORDS: Faunistics, herps, inventory, herpetological sample, transects

\section{INTRODUCCIÓN}

Los inventarios faunísticos son una herramienta esencial para el conocimiento de las comunidades. Los primeros inventarios herpetológicos en el País Vasco tuvieron lugar en la década de 1980 (Bea, 1985). Posteriormente, estos inventarios han sido utilizados en innumerables estudios de carácter local, generalmente a instancias de las Administraciones (véase Garin-Barrio et al., 2010, para zonas cercanas al área de estudio).

Jaizkibel es un territorio guipuzcoano emblemático que, inexplicablemente, cuenta con una información herpetológica muy limitada y que, además, podemos considerar obsoleta (Gosá \& Riofrío, 1983). La fuerte humanización de su entorno y los intensos episodios históricos a los que se ha visto sometido, tales como la urbanización, el pastoreo, las quemas periódicas de bosque y matorral, la explotación de los acuíferos o los usos militares, podrían verse ampliados con futuros macroproyectos que trasformarían drásticamente una parte significativa de su superficie, modificando la integridad y funcionalidad de sus ecosistemas.
El objetivo del presente estudio es la actualización de catálogo de anfibios y reptiles que pueblan el macizo de Jaizkibel, con una entrega preliminar de la composición herpetológica, la distribución de especies y sus preferencias de hábitat.

\section{MATERIAL Y MÉTODOS}

Área de estudio

El área del macizo de Jaizkibel seleccionada para el estudio coincide con los límites del Lugar de Importancia Comunitaria Jaizkibel (Fig. 1), con una altitud máxima de $547 \mathrm{~m}$. La mayor parte del mismo comprende la vertiente norte, además de las cimas y una pequeña superficie de vertiente sur en la zona central del enclave. La zona es Iluviosa (más de 1500 mm/año) y el relieve complejo, surcado de vaguadas y barrancos, abundante en roquedos y afloramientos rocosos, formado por materiales de areniscas calcáreas y lutitas dispuestas en estratos. Dominan los pastizales con matorral, brezales, helechales y argomales, producto de la deforestación. En el LIC se han 


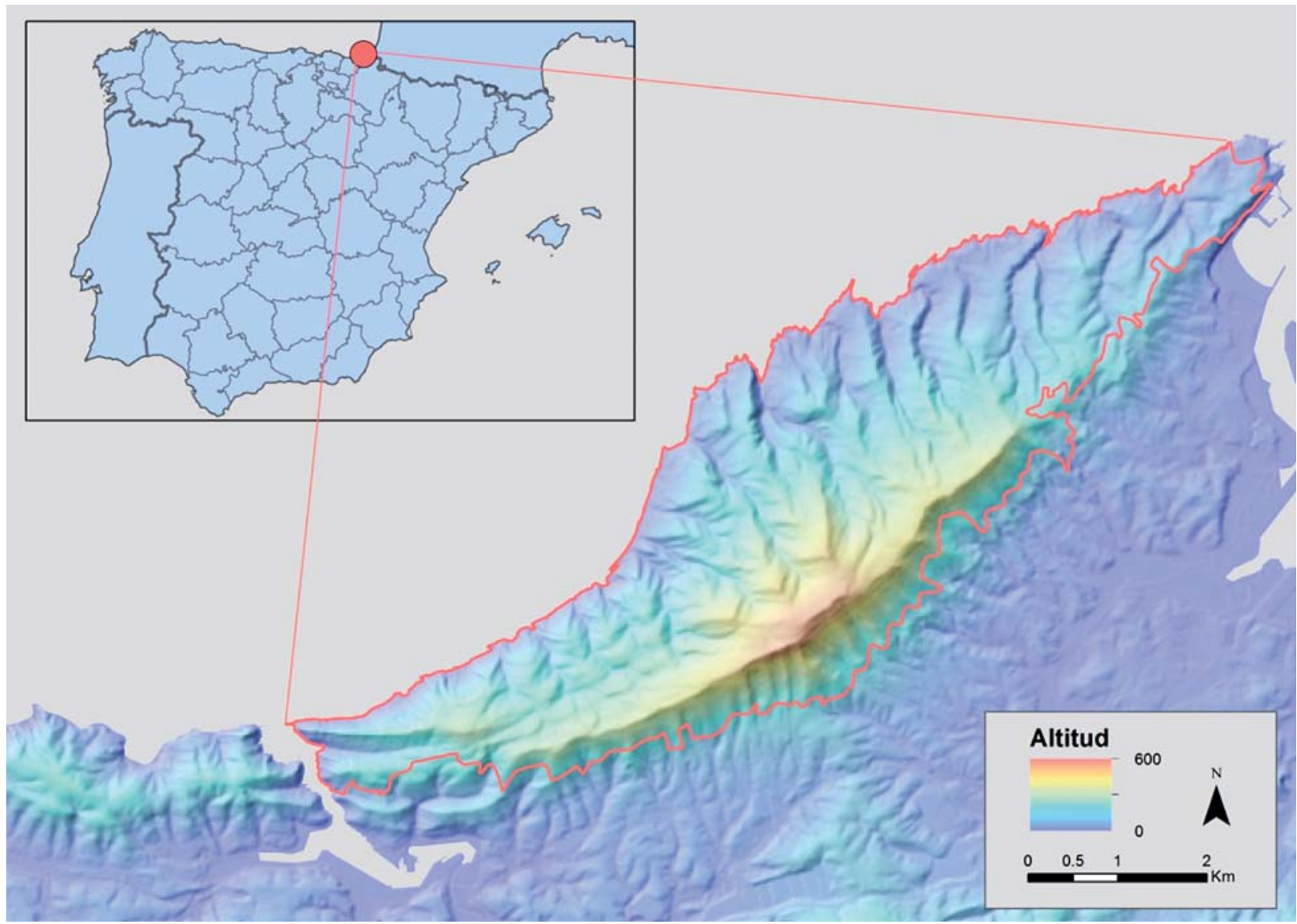

Fig. 1. - Límites del área de estudio, coincidentes con los del LIC Jaizkibel. 1. Irudia. Jaizkibel GKL-arekin bat datos, ikerketa arearen mugak.

censado 42 unidades EUNIS de vegetación (De Francisco, 2007), que a efectos de la caracterización del hábitat de los herpetos se han agrupado en 9 unidades simplificadas, a las que se han adscrito las observaciones: arroyos y sus riberas, charcas y estanques, argomales y helechales, brezales, pastizales, prados, prados-juncales, bosquetes caducifolios, roquedos y afloramientos.

\section{Muestreo}

El estudio tiene su base en un trabajo de campo realizado entre Abr. y Oct. de 2012, incorporado a una recopilación previa de la información disponible, que se reduce a lo publicado en el atlas herpetológico regional (Bea, 1985), a un estudio multidisciplinar del medio físico de Txingudi (Gosá \& Riofrío, 1983) y alguna nota específica (Bea, 1980). Cierto material recolectado en ejemplares de Podarcis liolepis (Boulenger, 1905) de Jaizkibel contribuyó a la realización de estudios genéticos (SanzAzkue et al., 2006) y etológicos (Iglesias-Carrasco \& Cabido, 2013). Se contó, además, con los datos inéditos recogidos por los autores de este artículo y otros naturalistas, acumulados en años precedentes, algunos en la misma época de las referencias citadas (década de 1980). Con toda esta información se construyó una base de datos con 218 observaciones registradas entre 2005 y 2012, a partir de las que se elaboraron los resultados aquí expuestos.

El trabajo de campo tuvo como objetivo la recopilación mediante muestreos de la mayor cantidad posible de información en un espacio lo más extenso posible, dentro de la amplitud del mismo y las posibilidades que ofrecía un estudio de estas características, no sistematizado, pero que, sin embargo, se realizó principalmente en periodos favorables para cubrir una parte de sus fines, la observación de reptiles, coincidiendo con su estación reproductora, entre Abr. y Jun. Por el contrario, los anfibios fueron muestreados fuera de este periodo, por lo que la mayor parte de las observaciones procedieron de ejemplares en fase acuática (larvas).

Se efectuaron 26 salidas diurnas de campo consistentes en recorridos por la red de caminos del macizo, llevados a cabo por 1-4 personas. La no realización de muestreos crepusculares o nocturnos pudo infravalorar el número de especies detectadas y su asociación con los hábitats que utilizan. Los itinerarios seguidos comunicaban entre sí las distintas cuencas, discurrieron por hábitats diversos y fueron determinados siguiendo un criterio de accesibilidad y de adecuación a la presencia potencial de especies. Se realizaron transectos de varios cientos de metros de longitud en las orillas del $77 \%$ de los cauces 
principales de la vertiente norte de Jaizkibel $(n=18)$. Dichos cauces son de corto recorrido, con una longitud media en torno a los $2 \mathrm{~km}$. Se prospectó especialmente las pozas de las regatas, donde se concentran las poblaciones larvarias. El $44 \%$ de las regatas principales se visitó en dos o más ocasiones (una de ellas, hasta seis veces). No se contabilizó el número de ejemplares observados, realizándose tan sólo muestreos cualitativos para la detección de las especies. Los hábitats preferentes de los reptiles, como roquedos y afloramientos, acantilados, bosquetes, argomales, brezales, prados y juncales, fueron muestreados sin seguir un transecto predeterminado, prestando especial atención a los microhábitats más favorables para las especies potencialmente presentes.

\section{RESULTADOS Y DISCUSIÓN}

\section{Comunidad herpetológica}

Los datos disponibles hasta el momento reducen la comunidad herpetológica de Jaizkibel a 4 especies de anfibios y 11 de reptiles, entre las que se ha incluido $L a-$ certa schreiberi Bedriaga, 1878 basándose en datos bibliográficos de hace más de tres décadas (Bea, 1980), no habiéndose vuelto a observar la especie en todo este tiempo. La ubicación estratégica de Jaizkibel para la comunicación biogeográfica con el continente, en el borde occidental de los Pirineos, es determinante cuando se analiza la composición de la comunidad: 10 especies tienen su origen filogenético en el continente europeo, dos son endémicas de la Península y otras tres se consideran subendémicas, originadas en la misma y expandidas hacia el norte, ocupando una parte más o menos extensa de Francia, y el sur, en el caso de Bufo bufo (=B. spinosus) (L., 1758), que colonizó el norte de África (Tabla 1).

En el último decenio, dentro de los límites del LIC Jaizkibel, se han registrado observaciones $(n=218)$ de todas las especies de anfibios y reptiles anteriormente citadas, a excepción de la ya comentada L. schreiberi. Como sólo en 2012 se han realizado los muestreos con continuidad, a lo largo de siete meses y bajo el objetivo propuesto, los cálculos correspondientes se han hecho

\begin{tabular}{|l|c|}
\hline Especie & $\begin{array}{c}\text { Origen } \\
\text { biogeográfico } \\
\text { Europea }\end{array}$ \\
\hline Lissotriton helveticus (Razoumowsky, 1789) & Europea \\
\hline Alytes obstetricans (Laurenti, 1768) & Europea \\
\hline Bufo bufo (Linnaeus, 1758) & Subendémica \\
\hline Pelophylax perezi (López Seoane, 1885) & Europea \\
\hline Anguis fragilis (Linnaeus, 1758) & Europea \\
\hline Lacerta bilineata (Daudin, 1802) & Endémica \\
\hline Lacerta schreiberi (Bedriaga, 1878) & Europea \\
\hline Zootoca vivipara (Jacquin, 1787) & Europea \\
\hline Podarcis muralis (Laurenti, 1768) & Subendémica \\
\hline Podarcis liolepis (Boulenger, 1905) & Europea \\
\hline Coronella austriaca (Laurenti, 1768) & Europea \\
\hline Coronella girondica (Daudin, 1803) & Europea \\
\hline Natrix natrix (Linnaeus, 1758) & Europea \\
\hline Zamenis longissimus (Laurenti, 1768) & Endémica \\
\hline Vipera seoanei (Lataste, 1879)
\end{tabular}

Tabla 1. - Composición conocida de la comunidad herpetológica en Jaizkibel. 1. Taula. Jaizkibelgo komunitate herpetologikoaren osaera ezaguna. exclusivamente con la muestra de ese año $(n=133)$. E mayor esfuerzo se invirtió en los meses de Jun. a Oct., con 4 o más muestreos, siendo Jun. y Ago. los meses más rentables, porque acumulan el $59,8 \%$ de las observaciones totales (Fig. 2). Aun cuando el número de muestreos fue alto, la menor frecuencia de registros se obtuvo en los dos últimos meses, coincidiendo con la fenología de las especies. Las únicas larvas de anfibios observadas entonces, y en baja densidad, fueron las de Alytes obstetricans (Laurenti, 1768).

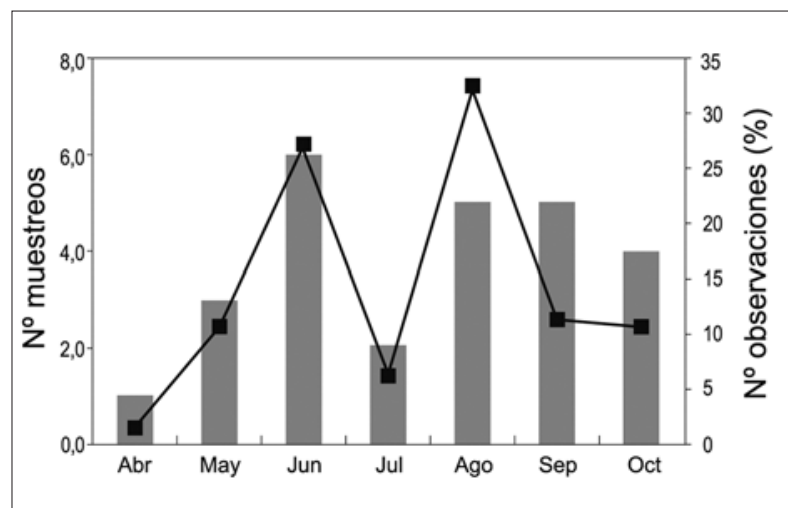

Fig. 2. - Número de muestreos (histograma) y porcentaje de observaciones (línea) de anfibios y reptiles en siete meses de muestreo en 2012.

2. Irudia. Laginketa kopurua (histograma) eta anfibio eta narrastien behaketa portzentaia (lerroa) 2012. urteko zazpi hilabetetan egindako laginketetan.

En 2012 se observaron 13 de las 14 especies citadas en el último decenio, a excepción de Coronella austriaca Laurenti, 1768 (Fig. 3). Las frecuencias de anfibios registradas denotan una presencia bastante equilibrada de las especies en los humedales, a excepción de Pelophylax perezi (López Seoane, 1885), que es la menos abundante. Las fases larvarias de los tres anuros y los adultos de Lissotriton helveticus (Razoumowsky, 1789), en su etapa final de la reproducción, ocuparon y compartieron

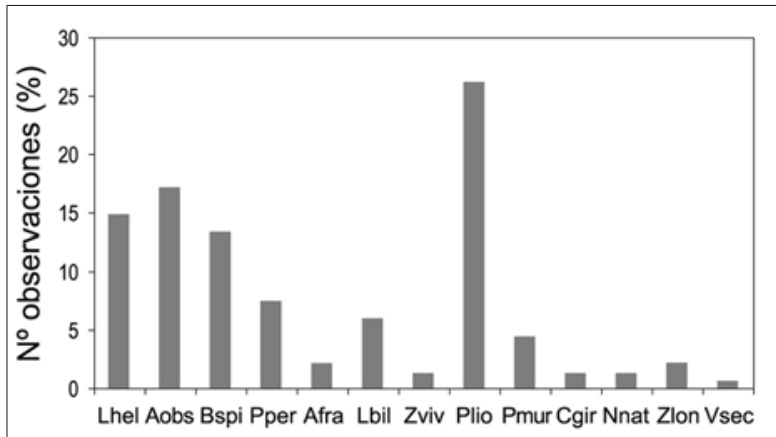

Fig. 3. - Frecuencia (porcentaje) de las observaciones de especies de herpetos en 2012 ( $n=133)$. Lhel: L. helveticus; Aobs: A. obstetricans; Bspi: B. spinosus; Pper: P. perezi; Afra: A. fragilis; Lbil: L. bilineata; Zviv: Z. vivipara; Plio: P. liolepis; Pmur: P. muralis; Cgir: C. girondica; Nnat: N. natrix; Zlon: Z longissimus; Vseo: V. seoanei.

3. Irudia. 2012an herpeto espezieen behaketen ( $n=133$ ) maiztasuna (portzentaia) Lhel: L. helveticus; Aobs: A. obstetricans; Bspi: B. spinosus; Pper: P. perezi; Afra: A. fragilis; Lbil: L. bilineata; Zviv: Z. vivipara; Plio: P. liolepis Pmur: P. muralis; Cgir: C. girondica; Nnat: N. natrix; Zlon: Z. longissimus Vseo: V. seoanei. 
una buena parte de las pozas de los arroyos donde fueron observados. Por su parte, la frecuencia de observación de $P$. liolepis fue netamente superior a la del resto de reptiles (Fig. 3), confirmando la impresión previa que se tenía, de que era una especie abundante y muy repartida por todo el macizo de Jaizkibel.

\section{Distribución}

Aun siendo fragmentarios los datos recabados (se incluyen aquí todos los del último decenio) la distribución de los anfibios en Jaizkibel, a excepción de P. perezi, se reparte por amplias zonas del macizo, aunque se observan particularidades que pudieran derivarse de la falta de muestreo de las regatas durante la estación reproductora. Esto podría haber afectado a los resultados de la distribución de $L$. helveticus y $B$. bufo, especies que probablemente realizaron una parte importante de su puesta con anterioridad al inicio de los muestreos en 2012 (Abr.). L. helveticus fue observado preferentemente en las pozas de la cabecera de los arroyos, mientras que las larvas de $B$. bufo se vieron con frecuencia en las pozas cercanas a su desembocadura en los acantilados. Al desconocerse los lugares de puesta de esta especie no puede afirmarse que seleccione las pozas más cercanas al mar, pudiendo ser arrastradas sus pequeñas larvas por la corriente de los arroyos. Sin embargo, las poblaciones larvarias de $A$. obstetricans aparecieron reparti- das por todo el macizo, tanto en la cabecera como en los tramos medios y la desembocadura de los cauces, lo que podría ser indicativo de una relativamente alta densidad poblacional y estaría en concordancia con la conocida extensa fenología de la especie. Se observaron larvas procedentes de la puesta anual y de, al menos, el año anterior, que habrían pasado el invierno sin metamorfosear. La limitada presencia de $P$. perezi puede ser más concordante con la situación real de la especie en Jaizkibel, dado que está fuertemente ligada a los ambientes acuáticos, que prácticamente no abandona durante todo su ciclo vital, salvo para colonizar nuevos enclaves. Las escasas observaciones realizadas estarían de acuerdo con su limitada presencia en el área de estudio, donde podría considerarse como una especie infrecuente, sustentada en unas bajas densidades poblacionales (véanse las respectivas distribuciones de los anfibios en la Fig. 4)

Las observaciones de reptiles fueron, en general, escasas, salvo excepciones, aunque todas las especies estarían repartidas por todo el macizo o buena parte de él. $P$. liolepis, el reptil más abundante, se concentra especialmente en los afloramientos situados en las vertientes medias de Pasaia y en la línea de los acantilados costeros más occidentales de Hondarribia. La especie domina claramente a su congénere Podarcis muralis (Laurenti, 1768), escasamente observada y siempre alejada de la costa, en los microhábitats menos expuestos a la insolación. El se-

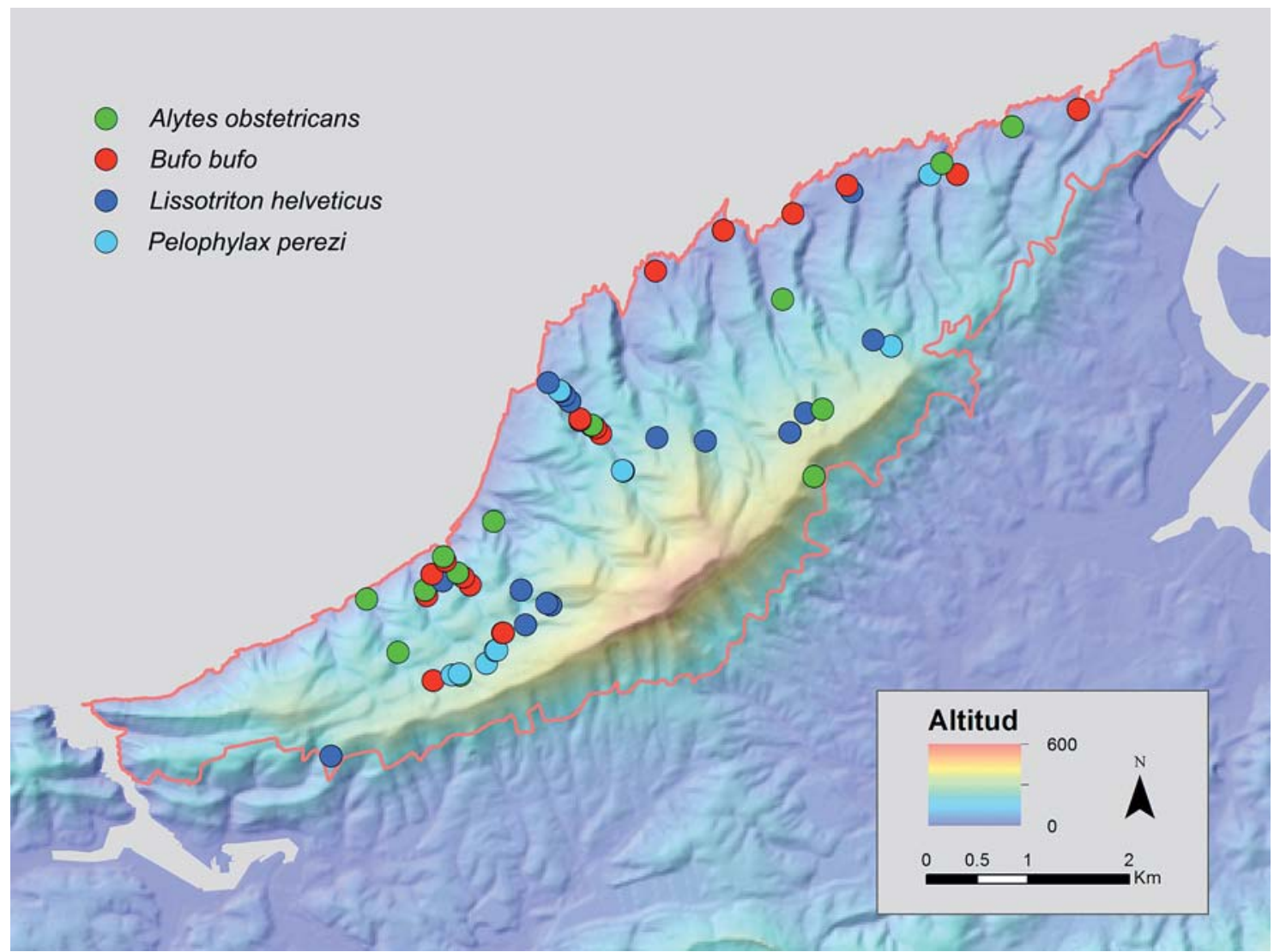

Fig. 4. - Puntos de observación de las cuatro especies de anfibios entre 2005-2012.

4. Irudia. Lau anfibio espezieen behaketa puntuak 2005-2012 urte bitartean. 
gundo reptil más observado fue Lacerta bilineata Daudin, 1802 (Fig. 5), en general también alejado de las zonas insoladas de la costa, por sus preferencias higrófilas. Las escasísimas observaciones de Anguis fragilis Linnaeus, 1758 no se corresponderían con la abundancia real de la especie, dados sus hábitos subterráneos y su relativa independencia de los espacios insolados. La potencialidad del hábitat para la misma es alta en Jaizkibel, por lo que su distribución y abundancia serán muy superiores a las observadas. Zootoca vivipara (Jacquin, 1787) se halla presente en la campiña circundante y montes del entorno, como Peñas de Aia (Gosá, obs. pers.). En el vecino Mendizorrotz, de características fisiográficas semejantes a las de Jaizkibel, se encuentra presente pero igualmente en muy bajas densidades (Gosá, obs. pers.). En Jaizkibel, tanto en el área de estudio como en el entorno de la marisma (zona de Jaizubia, Hondarribia), quedaría relegada a su hábitat más favorable, los prados, a efectos de la competencia con el resto de lacértidos y presentando en la actualidad poblaciones de baja densidad (véanse las distribuciones de los saurios en la Fig. 5).

Las frecuencias de observación de ofidios fueron las más bajas, como corresponde a la ecología y reducida abundancia de estas especies. Sin embargo, los puntos donde fueron contactadas se reparten por áreas dispersas del macizo, lo que sugiere una amplia distribución por el mismo, si bien sustentada en densidades poblacionales bajas y ocupando enclaves discretos, posiblemente separados unos de otros en algunos casos. La abundancia y extensión de grandes especies, como Natrix natrix (Linnaeus, 1758) y Zamenis longissimus (Laurenti, 1768), especialmente de ésta, debe ser mayor que la que se desprende de los datos recabados en el área de estudio, porque se posee un cierto número de observaciones en la ladera sur del macizo y la campiña periférica a Hondarribia. Por otra parte, no son infrecuentes en esa zona las observaciones de una pareja de águilas culebreras Circaetus gallicus (Gmelin, 1788) que anida en la ladera norte de Jaizkibel, cazando y portando grandes culebras (Rubio, obs. pers.), lo que podría indicar la existencia en este monte de densidades poblacionales relevantes de estas especies. Vipera seoanei Lataste, 1879 y C. austriaca son los ofidios más escasos, habiendo sido observados en el último decenio en una sola ocasión; la primera en vertiente sur en una zona próxima al cordal, en término de Pasaia, y la segunda en una zona media del macizo (Hondarribia) (véanse las distribuciones de las especies de ofidios en la Fig. 6).

\section{Uso del hábitat}

Como quiera que la mayoría de las observaciones de anfibios se efectuó en fase larvaria, esto ha permitido determinar la importancia de los arroyos en Jaizkibel como hábitat reproductor principal de todas las

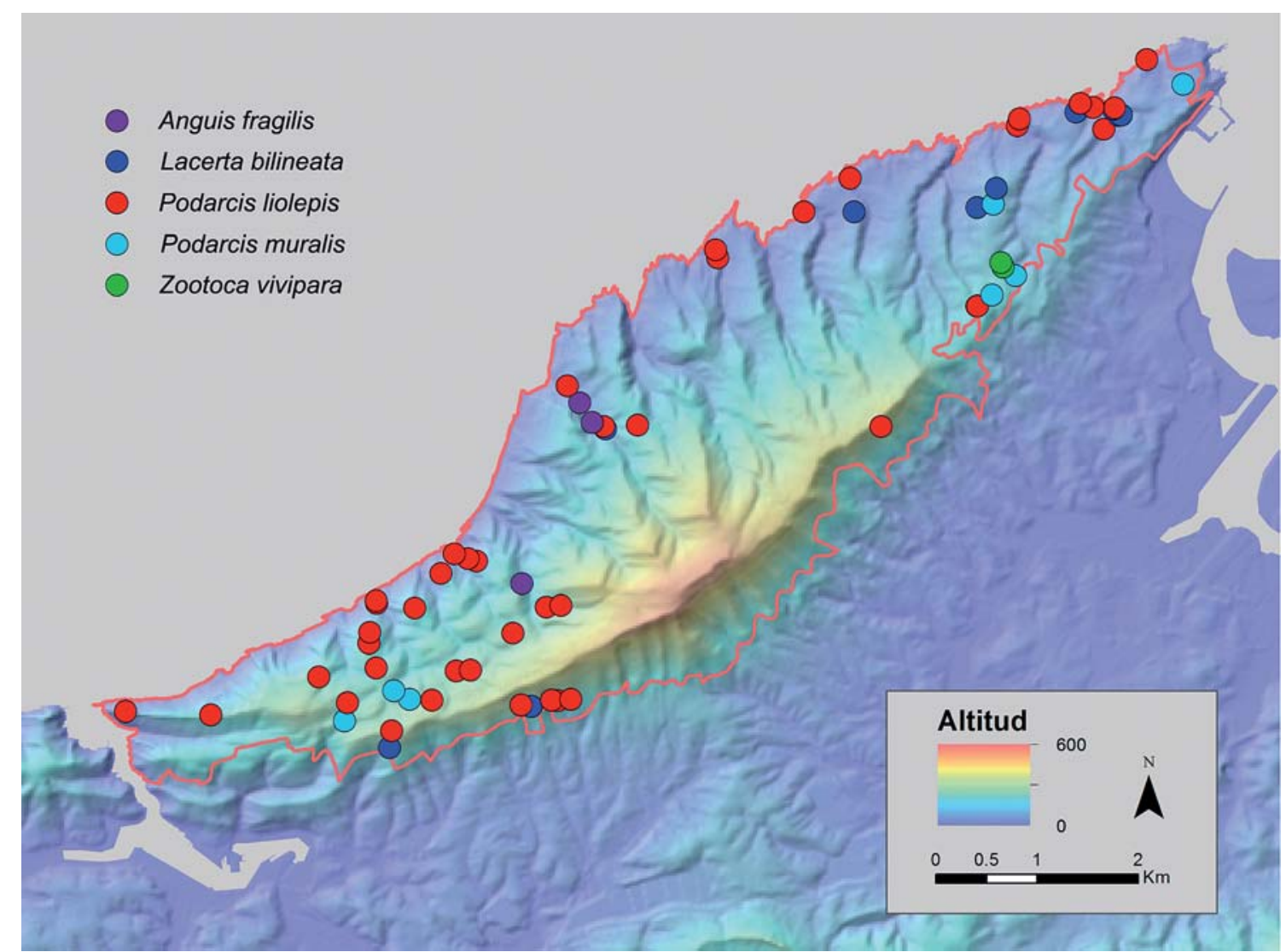

Fig. 5. - Puntos de observación de las cinco especies de saurios entre 2005-2012.

5. Irudia. Bost saurio espezieen behaketa puntuak 2005-2012 urte bitartean. 


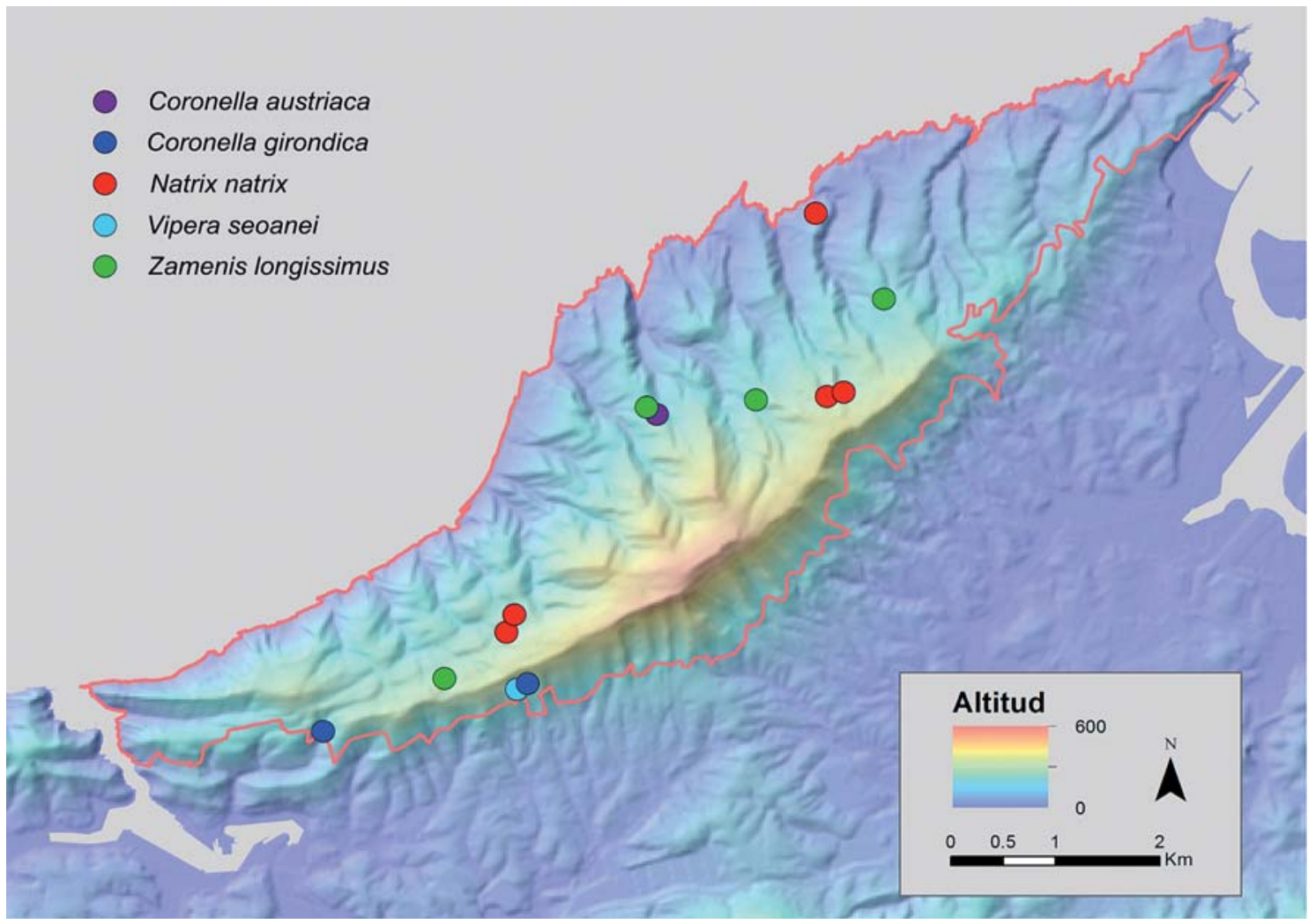

Fig. 6. - Puntos de observación de las cinco especies de ofidios entre 2005-2012.

6. Irudia. Bost ofidio espezieen behaketa puntuak 2005-2012 urte bitartean.

especies (Fig. 7), donde se obtuvo el 78,7\% de los registros. Sin embargo, la ejecución de los muestreos fuera del periodo reproductor de la mayor parte de especies no ha debido permitir la estimación correcta de su uso de los medios disponibles. El uso más diversificado del hábitat lo haría $A$. obstetricans, que se reproduce en cinco tipos diferentes de humedales.

Entre los saurios es $P$. liolepis la especie que ocupa un mayor espectro de hábitats, siendo la única presente en los afloramientos rocosos y acantilados, que constitu-

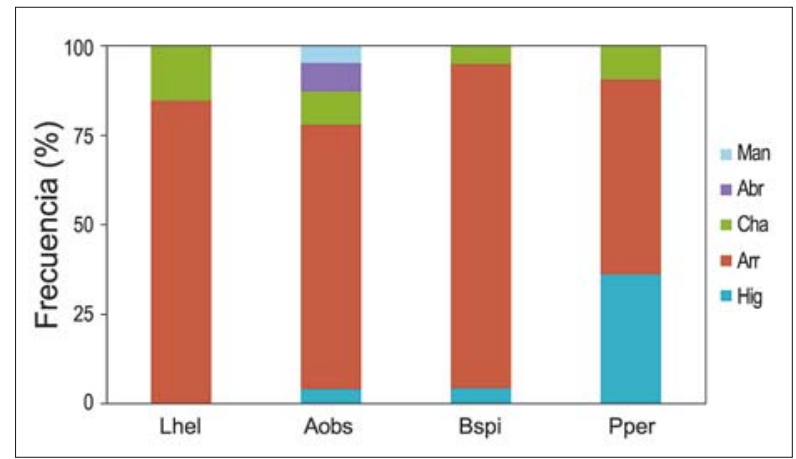

Fig. 7. - Distribución de las observaciones (\%) de anfibios según el biotopo de reproducción. Man: manantial; Abr: Abrevadero; Cha: charca; Arr: arroyo; Hig: prado higroturboso. Especies, según las siglas del pie de la figura 3.

7. Irudia. Anfibio behaketen banaketa (\%) ugaltzeko baliatu dituzten biotopoen arabera. Man: iturburua; Abr: uraska; Cha: putzua; Arr: errekastoa; Hig: larre-zohikaztegia. Espezieak 3. irudiko oinaren siglen araberakoak. yen su ambiente preferido, como corresponde a sus hábitos rupícolas. Su competidor, P. muralis, poco abundante en Jaizkibel, se recluye en los medios más frescos y cubiertos de los setos y pastizales. La cobertura densa de los herbazales y brezales, y los bordes de las masas caducifolias, arboladas y arbustivas, atraen a L. bilineata, presente también con cierta frecuencia sobre la vegetación de las orillas de los cauces (Fig. 8).

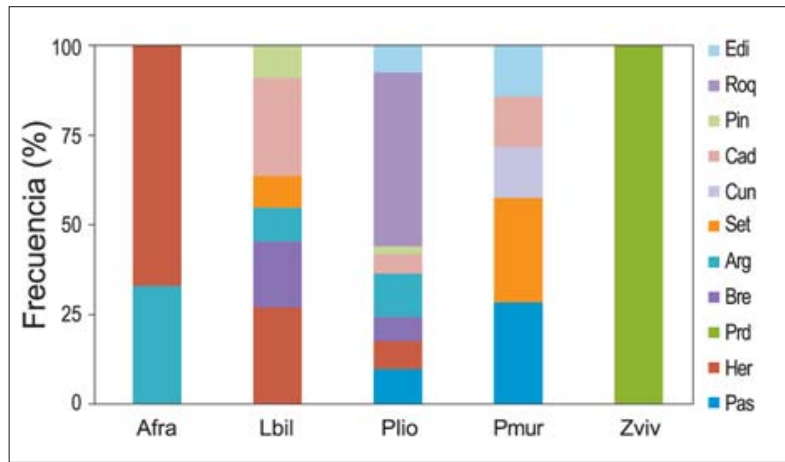

Fig. 8. - Distribución de las observaciones (\%) de saurios según el hábitat. Edi: edificación/ruina; Roq: roquedo/afloramiento/acantilado; Pin: pinar; Cad: caducifolio; Cun: cuneta arbustiva; Set: seto arbustivo; Arg: argomal-helechal; Bre: brezal; Prd: prado; Her: herbazal; Pas: pastizal. Especies, según las siglas del pie de la figura 3 .

8. Irudia. Saurio behaketen banaketa (\%) habitataren arabera. Edi: eraikuntza/hondakina: Roq: harkaiztegi/azaleratze/itsas-labarrak; Pin: pinudia; Cad: hostogalkorra; Cun: zuhaixkaz osatutako areka. Set: zuhaixkaz osatutako heskaia; Arg: otadi-iratzedia; Bre: txilardia; Prd: belardia; Her: belazea; Pas: Larrea. Espezieak 3. irudiko oinaren siglen araberakoak. 
Aunque los tamaños de muestra en ofidios fueron muy reducidos, los escasos datos obtenidos son concordantes para algunas especies con sus requerimientos espaciales conocidos (Fig. 9). Tal es el caso de N. natrix, que parece diversificar su hábitat en Jaizkibel, habiendo sido incluso vista depredando en charcos estacionales sobre las larvas del año de A. obstetricans (Sanz-Azkue, obs. pers.).

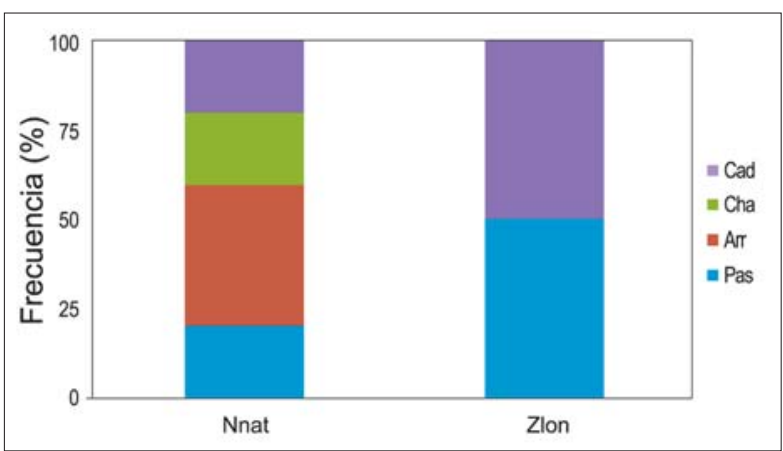

Fig. 9. - Distribución de las observaciones (\%) de ofidios según el hábitat. Cad: caducifolio; Cha: charca; Arr: arroyo; Pas: pastizal. Especies, según las siglas del pie de la figura 3.

9. Irudia. Ofidio behaketen banaketa (\%) habitataren arabera. Cad: hostogalkorra; Cha: putzua; Arr: errekastoa; Pas: Larrea. Espezieak 3. irudiko oinaren siglen araberakoak.

\section{CONCLUSIONES}

Los pequeños cauces de Jaizkibel, que discurren en paralelo a lo largo de todo el macizo, son el principal hábitat reproductor de los anfibios. Su corto recorrido y la presencia continua de pozas que funcionan durante buena parte del año como charcas, junto con la escasa distancia entre ellos, cumplirían el cometido de conexión entre las poblaciones, que podrían desplazarse latitudinalmente siguiendo la corriente o longitudinalmente colonizando las vertientes vecinas. La estructura del hábitat y la capacidad colonizadora de todas las especies del macizo son favorables a un poblamiento continuo del mismo, cuya distribución deberá completarse culminando el inventario ahora iniciado. La permanencia de los arroyos en su actual estado es fundamental para el mantenimiento de esta comunidad en las condiciones favorables que sugieren los datos preliminares aportados. No es descartable la presencia puntual de alguna pequeña población de Salamandra salamandra (Linnaeus, 1758), dada la estructura favorable de las regatas, con agua permanente y orillas que todavía mantienen representación de bosque ribereño umbrío, y la presencia de la especie en montes del entorno como Mendizorrotz (Garin-Barrio et al., 2010), de similares características.

La confirmación de L. schreiberi en Jaizkibel debe ser un objetivo preferente del muestreo herpetológico. La presencia relativamente abundante de microhábitats apropiados para la especie, como riberas vegetadas con afloramientos rocosos e insoladas, juncales encharcados en prados higroturbosos y pastizales húmedos, alimentan la esperanza del mantenimiento de algún pequeño núcleo de población, a sabiendas de la competencia desfavorable que L. bilineata pueda estar ejerciendo sobre su congénere, como habitualmente se ha puesto de manifiesto (Braña, 1984; Delibes \& Salvador, 1986; Gosá \& Lizana, 2007). Esta competencia, unida a la posición geográfica de la población en el extremo nororiental de distribución de la especie (Bea, 1985), podría estar contribuyendo a la aparente situación desfavorable para su continuidad en el macizo de Jaizkibel. Según la base de datos nacional (SIARE, 2013) la población más cercana de la especie se encontraría en montes del entorno de San Sebastián (Mendizorrotz), a unos $20 \mathrm{~km}$ en línea recta del lugar donde fue observada en Jaizkibel, si bien aquella cita no ha sido publicada y debe ser refrendada por observaciones, que hasta el momento no han tenido lugar, aun tratándose de un enclave ampliamente prospectado (Garin-Barrio et al., 2010).

\section{AGRADECIMIENTOS}

J.A. Belzunce (Ayuntamiento de Irún) contribuyó con sus observaciones a conformar la base de datos de este estudio. En los muestreos participaron compañeros del Departamento de Herpetología y otras personas. Nuestro agradecimiento a E. Uotila, C. Cabido, O. San Sebastián, E. González y A. Mitxelena.

\section{BIBLIOGRAFÍA}

Bea, A. 1980. Nota sobre la distribución del lagarto verdinegro (Lacerta schreiberi Bedriaga, 1878). Butll. Inst. Cat. Hist. Nat 45 (3): 185-186

Bea, A. 1985. Atlas de los Anfibios y Reptiles de Álava, Vizcaya y Guipúzcoa. En: Atlas de los Vertebrados Continentales de Álava, Vizcaya y Guipúzcoa: 55-99. Gobierno Vasco. Vitoria-Gasteiz.

Braña, F. 1984. Biogeografía, biología y estructura de nichos de la taxocenosis de saurios de Asturias. Tesis doctoral. Universidad de Oviedo.

De Francisco, M. (Coord.). 2007. Cartografía de hábitats, vegetación actual y usos del suelo de la CAPV. Gobierno Vasco.

Delibes, A., Salvador, A. 1986. Censos de lacértidos en la Cordillera Cantábrica. Rev. Esp. Herpetol. 1: 335-361.

Garin-Barrio, I., Rubio, X., Sanz-Azkue, I., Crespo-Diaz, A., Gosá A. 2008-2009. Análisis preliminar de la diversidad biológica en el entorno natural de Donostia-San Sebastián. Vol. 1: Resultados. Ayuntamiento de Donostia-San Sebastián. Disponible en web: http://www.donostia.org/info/ciudadano/ma_areas.nsf/vowebContenidosld/46A306C96006F215C 125785A0036E76C/\$File/AnalisisBiodiversidadDonostia_2008-2009.pdf

Gosá, A., Lizana, M. 2007. Lagarto verdinegro. Lacerta schreiberiBedriaga, 1878. En: Redacción del plan marco de gestión de los LIC de la Comunidad Autónoma de Cantabria: 1-13. Gobierno de Cantabria.

Gosá, A., Riofrío, J. 1983. Fauna. En: Estudio del Medio Físico de Txingudi. E. González (Coord.): 376-470. Viceconsejería de Medio Ambiente del Gobierno Vasco. Vitoria-Gasteiz.

Iglesias-Carrasco, M., Cabido, C. 2013. Adaptación a un nuevo ambiente: compromiso entre respuesta inmune y antidepredadora en una población urbana de lagartija. Panel. IV Congreso de Biodiversidad. Bilbao.

Sanz-Azkue, I., García-Etxebarria, K., Gosá, A., Rubio, X., Jugo B.M. 2006. Donostialdeko sugandila iberiarraren (Podarcis his panica) karakterizazio filogenetikoa. En: IX Congreso Luso-español/XIII Congreso Español de Herpetología: 231-232. Donostia-San Sebastián.

SIARE, 2013. Lacerta schreiberi. Consulta realizada en 30-10-13. www.siare.herpetologica.es 